\title{
I. On Professor Dœbereiner's new mode of producing fire
}

\section{Dr. J.S.C. Schweigger}

To cite this article: Dr. J.S.C. Schweigger (1824) I. On Professor Dœbereiner's new mode of producing fire , Philosophical Magazine Series 1, 64:315, 3-12, DOI: $10.1080 / 14786442408644545$

To link to this article: http://dx.doi.org/10.1080/14786442408644545

曲 Published online: 29 Jul 2009.

Submit your article to this journal

Џ Article views: 2

Q View related articles $\asymp$ 


\title{
PHILOSOPHICAL MAGAZINE AND JOURNAL.
}

\author{
$31^{\text {st }} J U L Y 1824$.
}

\section{On Professor Dombereiner's new Mode of producing Fire. By Dr. J.S. C. SCHweigger*.}

QUCH new and interesting phænomena as those of which $\omega$ mention has been made by M. Dobereiner, naturally excite the wish to connect them, if possible, with the series of other phænomena of nature already known. Every trial of this sort, however fruitless it may end, will at least contribute to show the object from more than one point of view, and by that means to facilitate the development of the mystery. The following observations were caused by a small publication, to which we wish to direct the reader's attention. It is entitled, On the newly discovered and very remarkable Properties of Platinum, and the Pneumatic Capillary Agency of cracked Glass; by J. W. Dœbereiner. Jena 1823. In this pamphlet, we find, in page 6, under the head " Fruitless Endeavour to explain satisfactorily the newly-discovered Property of Platinum," the following remark: "As the hydrogen is neither absorbed nor condensed by the metallic platinum dust, and yet the inflammability of the former so much heightened, when in contact with the latter, that it attracts oxygen in a diluted state, in which an electric spark cannot effect their union, the effect cannot be considered as resulting from any mechanical agency of the platinum ; but it must be supposed, in order to explain the phænomena satisfactorily, either that the hydrogen gas forms an electrical combination with the platinum, in which the former represents the exciting and inflammable agent, or the zinc, or that the entire phænomenon is determined by the peculiar form of the atoms of the platinum. On the former supposition, we must assume that hydrogen is a substance of a metallic nature; and on. the latter, consider the spongy platinum,

* From his Neue Joumal für Chemie, \&c. band ix. p. 211 .

Vol. 64. No. 315. July 1824.

A 2

with 
with M. Schweigger, as possessing a crystallo-electric power. -In order to examine these suppositions, I have made a great number of experiments, but have not yet obtained any result in confirmation of either. 1 brought into contact with the explosive mixture, entire and broken pieces of boracite, tourmaline, diamonds, finely powdered coal, graphite, silver and copper dust; and none of these substances effected, at common temperatures, a condensation of the gases. No condensation of hydrogen occurred when I placed it in contact with platinum dust, and the following substances respectively: peroxide of manganese, carbonic oxide, carbonic acid, nitrous gas, and other oxides. I further exposed the platinum dust to mixtures, 1st, of carburetted hydrogen and carbonic acid gas; 2dly, of olefiant gas and carbonic oxide; $3 \mathrm{dly}$, of the vapour of alcohol and carbonic acid gas; 4thly, of sulphuretted hydrogen and carbonic acid gas; but none of these mixtures became condensed or changed in their nature. I expected the reverse; for I thought that the elements of water, which are contained in all these gaseous mixtures, would act upon each other, and would by that means give rise to new combinations. This and many other experiments, by which I endeavoured to ascertain the relation of hydrogen gas, when combined with other substances, as in ammonia and sulphuretted hydrogen, olefiant gas and carburetted hydrogen, to platinum and oxygen gas, -convinced me, that the action of that metal is confined to mixtures of free hydrogen and oxygen gas; and that its action is probably of a pecculiar nature-that it is neither mechanical, electric, nor magnetic."

Although I perfectly agree with my friend Dobereiner, that these remarkable phænomena are owing to some new principle of nature, yet I am inclined to follow the hint thrown out by him in the passage just cited, to investigate these phænomena, after my own manner, on the principles of crystalloelectricity; and to combine with them other phænomena, the union of the observations on which will, perhaps, be useful for further investigations. An arrangement of a series of phænomena so as to connect any particular phænomenon with the whole, in a natural manner, is alone what we understand by a theory in physics. With respect to my electro-chemical theory, I am not satisfied, as is usually the case, by merely calling the chemical attraction an electrical one; by which change of name, it appears to me that but little is gained, so long as we do not refer the particular chemical changes of bodies to electrical laws, but continue to deduce them, in the old manner, with Dr. Black, from fixed caloric. The Voltaic battery has in a direct manner forced us to renounce the language of Black's 
theory of caloric in some particular cases. But while one says that the atoms or molecules of acids are electro-negative, because they move towards the positive pole, and that the atoms of bases are electro-positive, because they are attracted by the negative pole; while properties evidently belonging to the entire masses of bodies are thus ascribed to the supposed properties of their atoms-but little is actually gained; even without considering how relative the notions of acid and base are, by which alone the electro-chemical theory, which is grounded exclusively on the phænomena of the Voltaic battery, and which only expresses these phænomena in a more general manner, is often involved in great perplexity. It is curious, however, that other phænomena, much longer known and not less remarkable than those of the Voltaic battery-I mean the crystallo-electric phænomena-should so little have attracted the attention of philosophers, that they have not found their merited place either in the compendiums of natural philosophy or of mineralogy; but have been referred by the natural philosopher to the mineralogist, and by the latter again to the former, being merely mentioned occasionally in a note. It is therefore right to say, at last, to the neglected guest at the bottom of the table of natural philosophy, "Friend, approach nearer !" if it were only to see what would result when he should be seated at the top. I will therefore endeavour to deduce not only the chemical, but also the general attraction of bodies, from these crystallo-electrical laws; for which reason I must refer to preceding volumes of this Journal*. As we observe all bodies to divide according to their crystalline texture, which is even the case with the finest chemical precipitates, it is hard to conceive how it could have been supposed, that crystalline divisibility ends where our microscopic observations terminate; and that liquids consist of spherical atoms, so that the terms liquid and without form are synonymous; while the ideas of Matter and of Form are in their nature inseparable. The notion of a liquid being nothing else than that of an infinite mobility; that is, if we suppose that the universal attraction of bodies depends upon crystallo-electrical laws, by a liquid will be meant an electric indifference to all the crystalline differentials. Not only when we suppose the infinite limit of divisibility obtained, which supposition is unnecessary even in the mathematical analysis, the notion of crystalline differentials will disappear. But it is a shallow presumption, when we suppose, with the notion of

* See vol. v. pp. 49-74; vol. vi. pp. 250 , 254 ; vol. vii. pp. $302-$ 308 , and 515; vol. viii. p. 307 ; vol. xi. pp. 54, 330, 435; vol. xiv. pp. 510 -516 ; vol. xxy. pp. 158-173.

a liquid, 
a liquid, to have attained the limit of the infinite even in idea. On the other hand, we find, when we take experience for our guide, one and the same body-as for instance, acetic acid-at one and the same temperature appear as well in a crystalline as in a liquid or gaseous form, those states being dependent only on various pressures of the atmosphere*. And we knew long since, that in some experiments on the polarisation of light, some liquids produce effects which are dependent upon a crystalline double refraction of the rays of light; as for instance, camphor has in its solid state a double refraction, and reproduces, in the well known experiment of Malus, the double image which has disappeared; but it retains that property in its liquid state, of which I have convinced myself by an experiment instituted expressly for that purpose. The same is known to be the case with camphor dissolved in spirits of wine. Even polarisations like those of crystals of attractive or repulsive axes appear in some liquids. The crystalline nature of the differentials of many liquids can be proved, therefore, by direct experiment. In this our differential calculus of physics, the step is therefore unavoidably taken to consider the elastic fluids under the same point of view as I have done in the former series of this work (see vol. v. p. 60). Indeed this assumption, though at variance with the somewhat surprising notion commonly entertained on that subject, has already obtained the assent of several exact chemists + .

* The experiments of Mr.Perkins on this subject will soon be made known.

+ Compare, for instance, the Review of the principal Features of the present State of Chemistry; by Professor Von Ittner, Freiburg, 1823. On the other hand, I must be excused for not paying any attention to what $M$. Osann has stated in regard to my theory, in his Treatise on those substances which congeal 'when heated, and become liquid again upon cooling, inserted in Gilbert's Annals, vol. lxix. p. 283-300. M. Osann completed the greater part of this Treatise under my direction, and made most of the experiments contained in it in my presence, and in my laboratory. But it is to be wished that he had given a greater degree of perfection to his more recent labours, and particularly that he had paid more attention to the diminished solubility of lime, as also of several other substances at an elevated temperature. I must also refer him to some other things; particularly to the remarkable observation made by $M$. Bucholz on the crystalline precipitate of the sub-nitrate of bismuth, even when dissolved in an excess of water, by the mere increase of heat; which latter phænomenon M. Osann has cited, in p. 300, in a very incorrect manner, because he has not taken the trouble to read attentively the passage cited from Bucholz's Contributions to the Fxtension of Chemistry, No. II. p. 60, and No. III. p. 1. M: Osann has in every respect been precipitate in his publication. He has overlooked, in his hurry, that the theory which he considers as peculiarly his own, is the very same as that of M. Gay-Lussac, which I had mentioned in my Essay, which has been attacked, but scarcely read, by M. Osann : a theory which was given up by M. Gay-Lussac himself in consequence of his own further experiments.

The 
The phænomena of light, which appear by a sudden conpression of the air, but never on a slow compression of it, however powerful, will be deducible from an electric reversion, when considered under the same point of view, which is often indicated when bodies in the same electrical state are quickly moved towards each other, that the weaker electricity is opposed by the stronger, as is the case with magnets. It is an opinion which contradicts itself, to suppose that those appearances of light are owing to a mechanical expulsion of caloric which has been chemically fixed in the air. In order to cover a little this contradiction, it is said that the capacity of the air for caloric is diminished by compression: but this means'nothing else, we would say, but that light and caloric become free, because they become free. Besides this, such a peculiar explanation cannot assign any reason why those appearances of light are never elicited by a rapid compression of hydrogen or azote, but always in a high degree in that of oxygen orhalogen [chlorine]. Neither can the favourite theory of fixed caloric assign any ground of distinction in this respect with regard to the last-mentioned gases, since they, like the former, consist of a ponderable base and of fixed caloric. Why, therefore, does this fixed caloric appear with such strong light only in those gases which are attracted to the positive pole of the Voltaic battery, viz. in oxygen and in chlorine? According to my crystallo-electrical theory, I can with good reason assume, that the crystalline differentials of the last-mentioned gases repel each other with a predominant negative electricity, on account of their being attracted by the positive pole of the Voltaic battery at the moment of their becoming free. If therefore such gases are forcibly compressed, it is the positive electricity which is excited by the electric reversion of the poles of many rapidly approaching crystals. But it is known, that positive electricity possesses a strong radiating power, which negative electricity, constantly appearing in a faint light, is deficient in. It is therefore the latter, which according to our crystallo-electrical theory will appear in a strong compression of hydrogen, and generally of all those gases which are attracted to the negative pole. For this reason will the compression of such gases elicit caloric only, and not light. It should not be objected that a decided manifestation of electrieity has never been perceived in these appearances of light; for as the products of both electricities, viz. light and heat, are present, the appearance of the electricities separately cannot be expected. Moreover, the crystallo-electricity is here meant, which, as is well known, imparts itself but with difficulty, where it appears the more powerful, as is the case in 
the tourmaline. But every thing which facilitates the appearance of the electricity will be favourable to those appearances of light and caloric in the compression of the gases, according to my theory: and that this is really the case, I shall now proceed to show. The paper on "The Light produced by the Discharge of an Air-gun;" by Mr. John Hart, inserted in the Journal of Science, vol. xv. p. 64, affords an interesting confirmation of the theory now proposed, and shall therefore be given as an Appendix to the present essay. All the experiments made by Mr. Hart, in order to produce light by the discharge of an air-gun, failed, until he accidentally discharged some paper wadding, when he perceived a faint light, which, however, he could not reproduce by a repetition of the experiment. He therefore tried other bodies: but neither clean dry silk, woollen, paper, nor wood, would answer, and even shell-lac only succeeded occasionally; whilst sugar, but especially narrow slips of glass, never failed in producing the effect. It appeared at length that even some particles of lime or sand produced a luminous discharge, and that when sand or fragments of sugar were held at the muzzle of the air-gun, while the stream of air was rushing forth, they appeared luminous. We find this paper translated in the Annales de Chimie, tom. xxii. p. 436-439; and the Editors, in confirmation of Mr. Hart's results, observe, that when we blow with a clean pair of bellows on even the most delicate electrometer, no sign of electricity is obtained; whereas when the bellows contain a little powder or ashes, the electricity produced is very strong.

Mr. Hart explains these phænomena by the electrical friction of the bodies. But he will hardly be able to state, why the bodies which so easily become electric, as silk, woollen, and shell-lac, would not answer in his experiments; while it was only necessary to throw the silk on the floor, so that it might become dusty, for a luminous discharge to take place. With these experiments the following observation may be connected. I have received from General von Hellwig (who long since intended to make experiments on the compression of air by an hydraulic-press, like those lately instituted in England) a glass apparatus for producing fire by compression, constructed in a most convenient manner, like that represented by M. Thenard in his Traité de Chimie, tab. xxii. fig. 3. The polished bore of the tube in which the accurately fitting piston moves, is scarcely half an inch in diameter, whilst the glass forming the tube measures about an inch in thickness. The appearances of light upon the violent compression of the air are very easily perceptible in this instrument; and when a small piece of amadou is affixed to 
the hook of the piston, it usually becomes ignited at the first stroke, by a most vivid flash. W Wen the amadou is not used, a more powerful stroke is necessary for the production of light; and when the piston is perfectly clean, one may sometimes repeat the experiment ten times before that effect is produced.

The smallest piece of amadou, however, fixed to the hook of the piston, facilitates the evolution of the light, and heightens its brilliancy. Care only is to be taken that it may contain many fibres, and for that reason it should not be compressed with the fingers. It is strikingly manifested by this experiment that the amadou dóes not act a merely passive part when ignited by the flash, but that it contributes to the easier excitement of the light, which is too brilliant to be mistaken for the weak combustion of some points of the amadou, when glowing under the smoke. There can be no doubt that this is the fact, when we compare the experiment with those of Mr. Hart already cited. Now it is well known that the projecting fibres of amadou best adapt it for the absorption of electricity. It was lately announced in a French Journal, that this substance is particularly remarkable for this property of drawing electricity from electrified bodies, and that with rapidity and in great quantity: and MM. Lefèvre-Gineau and Pouillet have actually found that a piece of this substance absorbs electricity, when placed opposite to a charged conductor, at a greater distance than even a metal point. If it be made wet, however, this property, which evidently arises from its fibrous and spongy structure, becomes diminished*.

The amadou in the apparatus for producing fire by compression above described, operates altogether with the same modifications. I substituted for it metallic points, and they also appeared to a considerable degree to favour the appearance of light, though not to the same extent, as the action on such tender electrical crystals as our theory supposes to exist in elastic fluids depends so much upon the softness and abundance of the points.

Now let a metallic amadou be conceived; that is, the effect of metallic points united with the spongy structure; and this moreover in a metal, like platinum, easily ignited by electricity†; will not such a metallic sponge greatly facilitate the development

* See Gilbert's Annalen, band 73; or the new series, band 13, p. 127.

$t$ While copper is easily melted in a moderate fire, and platinum is infusible, they become reversed with respert to electric fire; from which latter circumstance it has usually been concluded, that copper is a far better conductor of electricity than platinum, which of all the metals is also the

Vol. 64. No. 315. July 1824. 
development of electricity by the agency of points, in mixtures of gases strongly opposed in electric polarity? and this in a greater degree proportionably to the tendency to development of the electricities under ordinary circumstances, that is, the further those gases are distant from each other in the electrochemical series, or the more powerful their inclination to combine. But we are unacquainted with more strongly opposed electro-chemical poles than oxygen and hydrogen, which are the extreme links of a series formed by arranging all bodies between the two wires of the Voltaic battery.

But why does platinum contribute in so distinguished a manner to this combination?-Because it is best adapted for a spongy mass, by its not melting in a common fire. The metals nickel and palladium may be added to platinum with regard to this latter aptitude. According to Dulong and Thenard"s observations, the "platinum in the spongy state strongly calcined, loses the property of becoming incandescent; but in this case, it causes the combination of the two gases slowly, and without a very sensible raising of the temperature *:" which is according to our theory, that if the points of the platinum sponge are made to melt in consequence of a strong calcination, and by which they lose their angles, the experiment, which is founded on the agency of points, will be less successful.

Agreeably to this theory I had offered the supposition, that platinum powder prepared by mechanical means would operate with still less energy; and this is really the case. In the same manner, a smooth and thin leaf of platinum does not operate until it is crumpled; which again shows the influence of points. The experiments which the French chemists made on the agency of some metals in the decomposition of ammonia, are beautiful and ingenions. 'The observation, first made by Thenard, is to be found at large in the former series of this Journal (see band vii. p. 299, \&c.), and even at that time I added an appendix, in order to explain this remarkable phrnomenon according to the laws of crystallo-electricity. In like manner the observations of Gay-Lussac on the decomposition of the vapour of prussic acid must be considered as supporting this theory (see band xvi. p. 14). MM. Dulong and Thenard, at the conclusion of their memoir occasioned by the ingenious experiment of Dobereiner, express the supposition,

worst conductor of heat. It is probable, however, that the ground of the former property lies still deeper, and perhaps in this newly-discovered principle. It may also be mentioned here, that M. Hildebrandt, in his Treatise on light emanating from electrical points, attributes to platinum a great power of exciting it.

* See Phil. Mag. vol. Ixii. p. 984 . 
that an opposition may exist between the noble and inferior metals, so far that the latter are favourable to the decomposition, and the former to the union, of gases. But this is very doubtful: for without considering that chemical combination and decomposition are not different in principle, and are under most circumstances inseparable, those very noble metals and their oxides are the most powerful agents in the decomposition of oxygenated water, that is, the expulsion of its oxygen with the evolution of caloric and light. The experiment with the aphlngistic lamp, which is the very reverse of M. Thenard's experiment with ammonia, most easily succeeds, next to platinum, with iron wire; in which therefore the iron, which promotes the decomposition of the ammonia as well as of the prussic acid, at an increased temperature, also favours the union of oxygen and hydrogen at the same elevated temperature. It is not to be denied that the experiment with the aphlogistic lamp depends also on the fullness of the points of contact; and that we therefore find the union of the gases to be favoured by the same circumstance by which the formation of crystals is promoted. When attentively considered, chemical and crystalline attraction will appear to be the same, as it is well known that every chemical precipitate appears in a crystalline form under the microscope. This is illustrated by a very interesting experiment made by my friend M. Vogel, a very ingenious chemist, formerly a resident at Bayreuth, whose early death was a great loss to the science. He first observed the combination of oxygen and hydrogen at a low temperature, under the influence of charcoal. It is true, that in this experiment charcoal impregnated with hydrogen must be employed, by which the atmospheric air becomes at the same time deoxygenated. If, however, one should be inclined to reduce that power of the charcoal to a mechanical principle, it should also be considered, that the hydrogen will be more perfectly divided, and most fully in contact with the oxygen, when mixed with the latter in a gaseous form, than when previously absorbed by the charcoal: and when we consider, moreover, that hydrogen not only adheres mechanically to the charcoal, especially when absorbed with water, but becomes condensed, it ought not to be forgotten, that hydrogen and oxygen may be greatly condensed in the gas blow-pipe, and will remain for years in that state, without combining with each other, when the compression is effected slowly and quietly. In this interesting experiment of M. Vogel likewise we find that the many points of contact effect the union of the gases. The effect, however, in this instance is more slow and feeble than in the experiment of Doxbereiner. 
This is what I had to state, from the crystallo-electric theory, respecting the new mode of producing fire, discovered by Prof. Dobereiner. I do not consider this explanation as entirely satisfactory; but I think it not unbecoming the present state' of natural philosophy, if at least I have succeeded in thereby connecting it with the other phænomena of nature: if any thing is to be advanced on this subject from the electro-chemical theory, it is only the crystallo-electricity that can throw any light upon it. As hydroguretted carbon stands near to the zinc in the positive electric series, while oxidated carbon is still more negatively electric than silver or platinum, it was certainly in that respect a very ingenious supposition of $\mathrm{M}$. Doebereiner, when he compared the activity of the hydrogen with regard to the platinum* to that of zinc; and that he so far thought of the excitement of electricity by contact. Soon afterwards, however, he renounced this theory, in his public reading before the Assembly of Naturalists at this place (Halle), which at present would be even less tenable, as even carbonic oxide gas is made to unite with oxygen by the platinum sponge, as we have just seen from the dissertation of the French chemists + . With regard to the electro-chemical explanation, it appears that the above view of crystallo-electricity alone remains.

For the illustration of the preceding Essay, I will add an encyclopedic review of my crystallo-electric theory, the consideration of which gains in interest on account of Dobereiner's important experiments. This will be nearly as published at a former period in the Universal Encyclopedia, conducted by Ersch and Gruber, under the article Attraction $\neq$.

II. Description of a Hydro-pneumatic Pump for compressing Gases or other elastic Fluids. By Mr. Samuel Seaward.

\section{To the Editors of the Philosophical Magazine and Journal.} Gentlemen,

THE accompanying description of an hydro-pneumatic pump, which I have invented for the pressure of compressing gas, would have been forwarded to you a long time back, but I was desirous of seeing the machine tried before $I$ offered it to the attention of the public. Being now fully satisfied on this point, as it performs all that was ex-

* See Phil. Mag. vol. Ixii. p. 291.

$\dagger$ Ibid. p. 285.

$\ddagger$ We purpose to give a translation of this account of the crystalleelectric theory in a future Number.-EDIT. 